\title{
Adding the Concept of Improving Product Value to a Design Project in a Course on Internal Combustion Engines
}

\section{Dr. John R. Reisel, University of Wisconsin, Milwaukee}

Dr. John R. Reisel is a Professor of Mechanical Engineering at the University of Wisconsin-Milwaukee (UWM). He serves as co-director of the Energy Conversion Efficiency Lab. In addition to research into engineering education, his efforts focus on combustion and energy utilization. Dr. Reisel was a 2005 recipient of the UWM Distinguished Undergraduate Teaching Award, a 2000 recipient of the UWM College of Engineering and Applied Science Outstanding Teaching Award, and a 1998 recipient of the SAE Ralph R. Teetor Educational Award. Dr. Reisel received his B.M.E. degree from Villanova University in 1989, his M.S. degree in mechanical engineering from Purdue University in 1991, and his Ph.D. in mechanical engineering from Purdue University in 1994. 


\title{
Adding the Concept of Improving Product Value to a Design Project in a Course on Internal Combustion Engines
}

\begin{abstract}
A senior technical elective course on Internal Combustion Engines has been taught by the author for many years. This course includes a major design project to be performed by the students. The project is very open-ended, allowing the students to explore particular aspects of IC Engine design that they find of interest. For most of the course offerings over the last 20 years, students were assigned, essentially, to design "something related to an IC engine". While allowing for a very open-ended project, this format led to some students struggling with the lack of direction in the assignment and others producing designs that were impractical or unrealistic.

To provide the students with more direction as well as to help develop the exploratory and entrepreneurial skills of the students, the project assignment was modified in the Spring 2018 semester. In the modified project assignment, student teams were asked to choose an engine that already exists, identify a component of that engine and propose reasons for why that engine component was designed in such a manner, and then to redesign the component to increase the value of the engine. Ways to increase the value include lowering costs, improving performance, and opening new markets for the engine. This format incorporates aspects of project-based learning into the course. While some students flourished under this new format, others struggled with various aspects in unexpected ways, and many groups were not particularly innovative in their projects.
\end{abstract}

In this paper, the two project assignments are discussed in detail, and the author's observations of student reaction and performance on the two types of projects are reported. Summaries of assessments of the projects are also provided. Suggestions are also made on modifying the project further in the future so that students may gain more from the design project experience.

\section{Introduction}

As we move deeper into the $21^{\text {st }}$ century, there are many calls to incorporate into engineering education more aspects that develop the creativity and entrepreneurship skills of the students. It is thought that for a nation or company to be more competitive and to develop solutions to more challenging problems, engineers need to be more than just technically competent; they need to be able to be innovative, creative, and willing to take risks.

Recognizing the importance of this goal, the author has modified a design project which is used in a senior-level technical elective course on Internal Combustion Engines. This course is taught in the Mechanical Engineering Department at the University of Wisconsin-Milwaukee (UWM). UWM has dual missions of research and access. As a result, the student population in engineering at UWM tends to consist of a higher percentage of under-prepared students entering the program than most engineering schools, but at the same time offers many undergraduate research opportunities for highly-motivated students. This brief profile of the engineering students will be important to keep in mind as the results of this project are discussed. 
The use of project-based learning ${ }^{1,2}$ is not new, and has taken on various forms at different institutions. For example, Ulseth et al. ${ }^{3}$ describe using a project that directly tied students to an industrial sponsor with a real-world problem that is addressed by the students. Torres and Sriraman ${ }^{4}$ partnered with actual industrial partners to place the students in a real-word scenario as it was being solved. Nespoli et al. ${ }^{5}$ used a case study approach for students to analyze a design of a disc brake system. Project-based learning has also been used in standard, traditional engineering science courses, such as Thermodynamics, to add context to the topical material being taught. ${ }^{6}$ It has also been used in foundational, introductory engineering courses where it can help push students out of their comfort zones for solving problems early in their engineering studies. $^{7,8}$ Project-based learning also can help build the softer skills sought after from graduates by ABET. 7

Curiosity can take many forms, ${ }^{9}$ but what is desired to be developed from the perspective of entrepreneurial thinking involves students asking why something is done in a particular way. This could be asking why a product was designed as it was, or why a series of processes is used to achieve a goal. This type of curiosity gives engineers the basis from which to create a new design or product, because once an engineer starts asking why something is designed the way it is, the door is opened for creative methods of an improving a product or solving a problem. Curiosity leads to creativity; one can certainly be curious without being creative and vice versa, but to be entrepreneurial, an organization needs to have people who bring these skills to the table. Engineers who have developed both traits have the advantage of being able to determine why something is done in a certain way and then be able to create an improvement to the product or process. This can lead to the desired entrepreneurial mindset where engineers approach their work with an eye towards creating value, either in products for others or society, or for themselves. ${ }^{10}$

The primary driving force behind the redesign of the design project in the Internal Combustion Engines course was to encourage curiosity in the students so that the student teams would be able to be creative in modifying existing engines to add value to the engines. Along the way, it was hoped to address shortcomings that had become evident over the years with the previous project. Below, the course is described, as is the previous project assignment. Some of the shortcomings of the previous assignment are explained. The revised project is then described, followed by observations of the results of the new assignment. Because the revised project has been used only once, a detailed study of its impacts has not yet been performed. Rather, general observations were made and are reported here, as are the results of some preliminary assessment of the impacts of the project as related to ABET student outcomes. These observations and assessment results will inform future modifications to the assignment to help better meet the assignment's educational goals. It will be more appropriate to perform a detailed study of the revised project's impacts at that future time.

\section{Description of the Internal Combustion Engines Course}

MechEng 432: Internal Combustion Engines is a senior-level technical elective course primarily taken by Mechanical Engineering undergraduate students nearing the end of their B.S. studies. The course can also be taken, with additional course requirements, by graduate students for graduate course credit. The course is offered every three semesters. The last three offerings of 
the course had between 42 and 50 students enrolled in each semester. Prior to that, the number of students enrolled was typically approximately 30 students a semester. Generally, between 1 and 3 graduate students are enrolled in the course, so that the course is populated predominantly by senior-level undergraduate students. When the revised project was introduced in the Spring 2018 semester, there were 40 undergraduate students and 3 graduate students in the course.

The course consists of a broad overview of primarily the thermal-fluids aspects of internal combustion engines. A weekly outline of topics covered is shown in Table 1. The course begins with a general overview of engines and engine terminology to bring the students to a common basic knowledge and vocabulary. General performance measures, such as mean effective pressure, volumetric efficiency, and fuel conversion efficiency, are then explored. Following this, the course considers engines from a big-picture viewpoint, looking at ideal cycles of operation and global chemical reactions for combustion processes. The course then walks the students through smaller-scale processes in the engines by considering how the working fluids (fuel and air) enter the engine, move inside the cylinder, transform into combustion products, exit the engine, and then experience processes to reduce pollutant emissions. The semester ends with a consideration of general heat transfer and thermal management issues, as well as a brief coverage of the fundamentals of engine lubrication.

The only prerequisite for this course is a course in basic thermodynamics. Most of the students will have also taken basic fluid mechanics, heat transfer, and mechanical design courses. However, knowledge from those courses is not assumed. The practical backgrounds of the students with regards to internal combustion engines vary considerably. Some students have spent many years tinkering with and modifying engines as a hobby, and some students have interned or worked as a co-op for companies designing and manufacturing engines or which use engines as part of their products. Other students have absolutely no experience with engines, and may not even have a theoretical understanding of the basic processes which engines perform during operation.

While the department maps this course as helping to fulfill several ABET student outcomes, ${ }^{11}$ the course is used to only a small degree in the formal assessment of the program's fulfillment of

Table 1: Weekly Topical Coverage in MechEng 432: Internal Combustion Engines

\begin{tabular}{|l|l|}
\hline Week & Topics Covered \\
\hline 1,2 & Introduction, Engine Nomenclature, General Operating Characteristics \\
\hline 3 & Engine Performance Measures, Calculations \\
\hline 4,5 & Otto Cycle, Diesel Cycle, Dual Cycle, 2-Stroke Cycles \\
\hline 6 & Combustion Chemistry \\
\hline 7 & Fuel and Air Intake Processes \\
\hline 8 & In-Cylinder Fluid Motion \\
\hline 9,10 & Combustion Physics \\
\hline 11 & Exhaust Processes \\
\hline 12,13 & Emissions Control \\
\hline 14 & Heat Transfer Issues \\
\hline 15 & Lubrication Fundamentals \\
\hline
\end{tabular}


these outcomes. In particular, the course is mapped to helping the program fulfill ABET student outcomes (a), (c), (e), (g), (h), (j), and (k), meaning that some components of the course are recognized as furthering the education of the students with regards to these outcomes. In its assessment activities, the department has chosen to formally assess student achievement of each outcome in selected courses, with a focus on a particular assignment, project, or test question being used for the assessment. Generally, the program uses required courses in the program for this formal assessment so that the department can be confident that all students are being assessed with regards to their meeting the student outcomes upon graduation. Some of the larger elective courses, such as MechEng 432, are used to provide additional assessment data on some outcomes. For example, MechEng 432 has been used for data on ABET student outcome (j): “a knowledge of contemporary issues"; this is assessed through use of a test question involving the impacts of different air pollutants from engines. Additional informal assessment occurs throughout the curriculum, as instructors recognize shortcomings and strengths in the student performance in their courses. This informal assessment can contribute to the interpretation of the formal assessment data.

Historically, this course has had a design project which determines $25 \%$ of the course grade. (This project was not used as part of the formal ABET assessment of student outcomes by the department.) The project could either be performed by an individual or as a team effort (with team sizes limited to no more than 4 students). Because there are many elements of internal combustion engine design that are not specifically discussed in the class, the design project gave students the opportunity to learn about aspects of internal combustion engine design that were of particular interest to them. Below, the previous format of the design project is discussed, followed by a description of the revised project.

\section{Description of Previous Design Project Assignment}

Prior to the Spring 2018 semester, the same basic format for the semester design project in MechEng 432 was used since the late 1990s. The deliverable by the students would be a written report, while some students also submitted a physical prototype as part of their project. The project direction was kept very open-ended. Essentially, the project assignment asked the students to design something involving or related to an engine. Examples of the types of student projects performed include (1) modifications of an engine component for an existing or theoretical engine, (2) a computer program for engine analysis, and (3) a cut-away engine for use as a demonstration of engine operation. Approximately 5 weeks into the semester, students were required to submit a one-page project proposal for approval by the instructor. Projects were modified at that point if they were viewed as too ambitious, too simplistic, or insufficiently defined. Students had the opportunity to modify the proposal and obtain instructor agreement to the changes during the semester up until 2 weeks before the project was due (which was in the last week of the semester). This was important because the projects were graded with consideration of what the students had proposed to do. So, suppose that the student team proposed to redesign 5 engine components and this was what the instructor agreed to for their team. If their final project only involved the design of 2 components, the project grade was lowered because it did not meet the expectations set out in the proposal and agreed to by the instructor. 
If the project involved the design of a new engine or engine parts, students were expected to prepare a report that provided enough information and detailed drawings so that someone could take the drawings and manufacture the new product; students sometimes supplemented this with a physical prototype. Students who wrote a computer program for engine analysis or designed a new test procedure for engine performance were expected to prepare a report that contained this product and thoroughly documented the product. Students who completed a physical prototype or computer program generally produced more complete designs, but due to cost and facility limitations such physical prototypes were not required. It was expected that students would also present some rationale for their design but did not need to conduct any experiments to prove that their design achieved the intended goals. For example, a team might have re-designed an engine exhaust manifold to increase power. This could only be confirmed through testing, but as equipment (and funds) may not have been available to build the prototype and test it, the students would only need to have a logical basis and modeling results for their design rather than definitive test results.

\section{Observed Shortcomings of the Previous Assignment}

Over the years of using the previous design project assignment, many good projects were produced by students in MechEng 432. Often, these projects grew out of the personal interests of the students by tapping into activities that the students did on their own modifying internal combustion engines outside of the course. Other times, good projects stemmed out of experiences the students had with internships or co-ops working for engine companies. While some strong projects were produced by students with little experience with engines outside of the course, many of the projects submitted by such students had significant shortcomings. Some of the more common project shortcomings that existed with the previous design project assignment are described below. The shortcomings were identified through the review and assessment of the student written project reports and through interactions between the instructor and the students as they worked on their projects.

1) Difficulty in Defining a Project Idea. With the previous assignment, recognizing the very open-ended nature of the assignment, the instructor provided the students with a list of 5 sample project ideas, as well as a reminder that the textbook ${ }^{12}$ used in the course had "Design Problems" at the end of every chapter. While not all of these textbook design problems made good projects to satisfy the assignment, they were another source of ideas from which a design project idea could be built. Despite this input, some project teams would come to the instructor seeking ideas for the project as the deadline for the project proposal neared. Thus, some students had difficulty beginning to identify an area of an engine that they were interested in learning more about through the design project. The flexibility in allowing the students to pursue their own interests seemingly overwhelmed some students whose previous experiences with engines were few.

2) Use of Early Course Topical Coverage for Project Idea. Some students each semester had a similar problem to those described in the first shortcoming, but dealt with it in a different manner. Rather than seek out the instructor's opinions for a project idea, some student teams proposed and executed rather simplistic projects based on the general overview material covered early in the semester. For example, some student teams would write a computer program to 
perform Otto Cycle calculations. While students might have added a few complexities to their programs, and some would try to use the results to analyze engine behavior, the design projects were not achieving the goal of having the students to delve more deeply into an aspect of engine design to become more knowledgeable on that aspect of an engine. The practical use of such programs is also questionable.

3) Projects that Lacked Practical Application: Many of the projects that were produced by students over the years had little practical application. The designs that students produced either were not based on actual engines (with the students instead using assumed dimensions), or were not grounded in logical theory to support claims of improvements. For example, a team could have designed a new air filter housing for an engine, without having any rationale as to why this redesigned filter housing would improve the engine.

One shortcoming that is difficult to overcome is the use of simplistic analyses by the students to study their designs. For example, students tend to fall back on a basic cycle analysis (such as the Otto Cycle) to predict temperatures and pressures in their engine. While this shortcoming is somewhat problematic, it is understandable due to the resource and time constraints on the project under which the students worked while developing these often theoretical designs.

It should be noted that because the project was not used for formal assessment of ABET student outcomes, the assessment of student work leading to these observations was informal in nature. However, these observations helped provide informal input to the department with regards to potential shortcomings in the program with regards to ABET student outcomes (c) and (k). ${ }^{11}$

To address some of the shortcomings of this design project assignment and to increase some of the entrepreneurial skills of the students, a revised project was developed and is described below.

\section{Description of New Design Project Assignment}

In the Spring 2018 semester, the design project assignment in MechEng 432 was modified in attempt to develop increased curiosity and creativity among the students. The project remained a team project (with up to 4 students on a team), with the possibility remaining for a student to do the project independently if a compelling reason existed. The primary change in the project is that students were to design a modification to an existing engine to increase the value of the engine. Value was defined broadly, and included such possibilities as (1) the purpose of the engine modification being to improve the engine performance in some way, or (2) maintain the performance of the engine while reducing its cost, or (3) modifying the engine to add potential uses for the engine (which would increase the number of people who might choose to buy the engine). Students were told that it was acceptable to increase the value of the engine in one way while decreasing its value from some other viewpoint. For example, a team of students might have modified an engine to improve its fuel efficiency but increased the cost of the engine with the modified part; in such a scenario, the performance improvement might entice a buyer to choose the engine despite its higher cost (even though the higher cost might discourage others from buying the engine). 
To approach the project, students were to choose an existing engine, preferably one for which they could obtain technical data such as part dimensions and general engine performance data. The team was then asked to choose a particular component of that engine, such as an intake manifold shape, or a lubrication system, or a valve size, and then develop reasons why they thought that the component was designed as it was. For background, some possibilities suggested by the instructor as reasons for component designs included the function of the component, engine performance, cost, meeting the configuration constraints of the application, and styling. The teams then made a short oral presentation to the class presenting their engine, the component under consideration, and their reasons that they had for the design choices made by the designers. The class was then able to provide feedback on the team's analysis, which gave the team additional input into why a component may have been designed as it was. A week later, the teams submitted a 1-page written summary to the instructor presenting the engine they chose for analysis, the component selected for study, and the reasons they think were behind the design choices made in the existing design. The summary also contained what the team hoped to achieve with their redesign of that component to increase the engine's value. It should be noted that teams could change their engine, or their component, or their reasons for the design of that component between their oral presentation and the written summary. While no teams did this, it was given as a possibility in case teams realized during their oral presentation that their original idea for the component redesign was not feasible or practical.

Students then needed to perform their redesign of the engine component and submit their final report. Students had approximately 2 months to complete this after the submission of their summary/proposal. The final report was to include a description of the current engine, their analysis of the reasons why the particular component that they were redesigning was designed as it exists, the goal or purpose of the redesign including how the redesign is expected to add value to the engine, a thorough description of the new design, including any necessary engineering drawings for the component to be built, and an analysis of the likely success of the redesign actually increasing the engine's value. Note that, depending on the project, this added value and the likely success of the redesign may be speculative. Without dedicated funding to support the building and testing of the new components, many teams might not have had access to the resources needed for such testing. In such cases, the teams needed to conduct as detailed a theoretical analysis as possible to justify their redesign and their arguments behind why their design added value. However, some teams were able to build and test their redesigns, and while the tests may not have always been ideal, they did represent a reasonable effort to obtain supporting data. In addition, if a team wished to redesign an engine to open a new market for the engine (for example, if they wished to rearrange engine components to fit the engine into the envelope of a different application), they were not expected to perform a market analysis as to whether or not the engine would be used in that application.

This revised project can be viewed as being in its development and refinement stages, and as such was not considered for inclusion in the formal assessment process of ABET student outcomes for the department. However, this revised project can help contribute to the meeting of ABET student outcomes (c), (e), (g), (h), and (k). Whether the project is to be used in future formal assessment of some of these outcomes (or rather, the revised outcomes that begin to be used in 2019-20) has yet to be determined by the department. However, the likelihood of the 
project being added to the formal assessment of ABET student outcomes is not high, due to the course being elective in nature.

\section{Observations from the First Offering of the Revised Design Project Assignment}

Fourteen projects were completed in the Spring 2018 semester under the new design project assignment. A brief description of each, along with the desired improvement in the value of the engine are listed in Table 2. The observations discussed below are based upon assessment of the students' written and oral reports by the instructor, interactions between the instructor and the students as the students worked on their projects, and a review of the topics of the projects.

Table 2: Description of Design Projects Submitted in Spring 2018 semester.

\begin{tabular}{|c|c|c|}
\hline $\begin{array}{l}\text { Project } \\
\text { Number }\end{array}$ & Brief Description & Value Improvement \\
\hline 1 & Open / Close intake valve by pressure (not spring) & Reduce Weight \\
\hline 2 & $\begin{array}{l}\text { Modify an L-Head engine to Overhead valves (changing } \\
\text { the compression ratio) }\end{array}$ & Increase Power \\
\hline 3 & $\begin{array}{l}\text { Change piston dome shape to decrease the compression } \\
\text { ratio }\end{array}$ & $\begin{array}{l}\text { Increase Power / } \\
\text { Efficiency }\end{array}$ \\
\hline 4 & $\begin{array}{l}\text { Change air intake system to draw in colder air further from } \\
\text { the engine }\end{array}$ & $\begin{array}{l}\text { Repurpose for a } \\
\text { different application } \\
\text { and increase power }\end{array}$ \\
\hline 5 & Make less restrictive air cleaner and breather element bolts & $\begin{array}{l}\text { Keep oil out of cylinder } \\
\text { and increase power }\end{array}$ \\
\hline 6 & Redesign camshaft and cams & Increase power \\
\hline 7 & Create variable valve lift with 3 cams per valve & $\begin{array}{l}\text { Allow small engine to } \\
\text { operate at different } \\
\text { speeds }\end{array}$ \\
\hline 8 & Redesign a coolant cross-over pipe & $\begin{array}{l}\text { Reduce pressure losses } \\
\text { in cooling system and } \\
\text { provide more uniform } \\
\text { cooling }\end{array}$ \\
\hline 9 & $\begin{array}{l}\text { Insert a direct fuel injection system into an existing engine } \\
\text { (design not complete) }\end{array}$ & $\begin{array}{l}\text { Increase efficiency and } \\
\text { power }\end{array}$ \\
\hline 10 & Change venturi and jet sizes in a carburetor & $\begin{array}{l}\text { Increase power, fuel } \\
\text { efficiency, lower } \\
\text { emissions }\end{array}$ \\
\hline 11 & Redesign crankshaft in very small engine & Increase power \\
\hline 12 & Cam testing and redesign & $\begin{array}{l}\text { Increase power (not } \\
\text { clear) }\end{array}$ \\
\hline 13 & Change bore diameter of a small engine & Increase torque \\
\hline 14 & Increase compression ratio of a utility engine (incomplete) & $\begin{array}{l}\text { Reduce fuel } \\
\text { consumption }\end{array}$ \\
\hline
\end{tabular}


First, it must be considered how well these projects addressed the shortcomings identified in the projects submitted in the previous assignment. With the process for completing intermediate steps in the project better defined, all student teams were able to identify a potentially suitable project as well as an engine to which the project would be applied. Continuing along with this trend, most of the students were not relying on project ideas from the material covered in the first month of the course. Project \#13 did focus on material covered early in the course, but the general idea behind the project was more elaborate than what was discussed in class during lecture. Project \#14 also tended to lean on material from early in the course, which did lead to issues with the lack of a firm focus in how the compression ratio was to be increased. Perhaps most importantly, all of the teams had a clear goal in mind in terms of how their project would potentially increase the value of the particular engine that they were modifying. This observation was identified through the written project reports submitted by the students. The projects were grounded in solid reasoning in terms of making a modification to improve the value of the engine in a specific way. While some projects submitted under the previous assignment did this, by directing the students through a careful thought process all teams were able to at least propose a project that met this goal and were able to elaborate on their reasons why the projects were achieving improved value for the engines.

While the new assignment did help many students by providing more structure to their projects and resulted in all groups being able to identify an area in which they could improve the value of a specific engine, there are some general observations that can be made regarding the success of the students in meeting the project's educational goals. An examination of the project subjects in Table 2 shows that the scope of most of the projects was not particularly creative or ambitious. This is also supported through assessment and evaluation of the written project reports, in which students detailed their designs and provided their rationale for their design choices. In other words, most teams did not propose a particularly novel idea to apply to the engine that they were considering. Considering that the internal combustion engine is a well-established technology, this may not be that surprising. However, if the students were as a group inclined to take on more challenging projects, there may have been more projects along the lines of \#9, where a group attempted to take a newer technological development and apply it to an older engine. (It should be noted that project \#9 did not result in a completed design.) Possible reasons for this include students not being interested in devoting additional time to an elective class that may not be a primary interest for them, or students being concerned about getting into a project too deeply and finding that they were unable to complete it. Alternatively, it is possible that the students' creativity has not been nurtured particularly well through several years of college before they reach senior standing; as a result, they were not able to generate more innovative ideas for a project.

Another observation on the projects is that many students struggled to come up with reasons as to why a component of an engine was designed as it currently existed. Some students with more background with engines were able to develop good reasons for someone else's design choices, but this is an area where more time needs to be devoted in the future. However, through evaluation of the content in the oral presentations and written reports, it was apparent that many groups did not look very deeply for reasons as to why current design choices may have been made, which potentially indicates a lack of curiosity on the part of the students. It may be 
indicative of students' curiosity not being nurtured well in their college studies. Again, this may indicate a need for curriculum modifications throughout the program so that students develop their curiosity and analysis skills in addition to calculation skills. One way to improve this approach during this class would be to take a sample engine in class and walk through a few specific components of that engine to lead the class through an analysis of why a component might have been designed in such a manner.

One shortcoming of some of the projects was the inability of students on some teams to find much data on the engine that they selected for redesign. Students who had physical access to the engine they were analyzing were able to make measurements on engine component sizes, and such data is available for many engines on-line. However, some teams struggled to find data on engine component size or engine performance for their engine of choice. Engines are available from the course instructor, so this problem should not occur in the future provided students are made sufficiently aware that they can make measurements at UWM on physical engines if necessary. Therefore, it is important that at least a few sample engines be made available to the students if they can not find information on another engine.

The feedback received from the rest of the class by most teams was minimal during the oral presentations on their component analysis. While it is still a worthwhile exercise to attempt as part of the project, it was apparent that some changes are needed to encourage more suggestions from the class. This will probably involve providing students who provide constructive feedback and suggestions with a reward, such as extra credit points on the project. It may also be a good approach to use a written feedback mechanism, where students write their suggestions down and submit them to the instructor, who would then pass them along to the students anonymously.

Overall, the revised assignment did significantly reduce some of the shortcomings that existed with the previous assignment, and provided students with a better educational experience overall. Students with the type of background that led to successful projects under the old assignment were able to easily adapt from the very open-ended approach used previously to the more structured and focused approach used in the new assignment. Having students consider adding value to an engine also greatly reduced the number of somewhat pointless designs being submitted. The issue involving students using rather basic analytical techniques to perform calculations remained for some groups - but that may be expected due to limitations on time and resources available to the students. If we consider the impact of the project on the goals of improving curiosity and creativity among the students, it should be noted that most teams did not display significant amounts of either through their reports. Regarding curiosity, it was hoped that students would demonstrate this by choosing components of the engine for analysis that were not routine, and then develop well-thought out reasons for why a previous design was created as it was. For most groups, either fairly straight-forward components were chosen for analysis or the reasons chosen for previous design choices were not particularly well thought through (or both). More curious students would have been expected to give much more thought to reasons behind design choices and to give more thought to how that design element fit in with the whole engine.

Similarly, creativity was encouraged through the students redesigning the engine to add value. As mentioned above, most teams did not attempt a particularly creative design, choosing to stick 
with simple changes that seemed to be done with an eye towards minimizing the work done on the project. While this is certainly not an unusual strategy for students, it also did indicate that many students were not challenging themselves to be more creative and take risks.

The last point to be made is that a goal of this redesign of the project assignment was to help build skills that would be needed for entrepreneurial thinking - curiosity, creativity, and adding value. For some teams, this was a successful project for the students in this sense as students were given an opportunity to exercise their curiosity and creativity while keeping in mind the importance of adding value to a product through their work. But many students did not demonstrate these attributes to a great extent, other than acting on the concept of adding value to the engine. This is an important lesson for the Mechanical Engineering program at UWM as faculty in that program look to increase the entrepreneurial thinking of their students. Curiosity and creativity skills need to be developed and fostered throughout the curriculum, and not delayed to certain courses near the end of the students' undergraduate careers.

It should be noted from the above observations that much of the assessment of the student work on the projects was done with an eye towards improving the project in future offerings of the course rather than to support the department's assessment of ABET student outcomes. Therefore, the discussion above was focused on very specific goals of the project, which do not necessarily correspond directly to an ABET student outcome. However, just as with the original project, we can still perform some informal assessment of relevant ABET outcomes based on assessment of the oral and written project reports, as well as interactions with students as they worked on their projects; this assessment can contribute to the department's deliberations on how well it is meeting the student outcomes overall. Based on this assessment, overall the teams were demonstrating that they understood the concept of increasing the value of a product, and were able to bring in economic considerations into their product designs at the level one would expect of an engineering graduate (part of outcome (c)). With regards to outcome (f), students were able to better formulate engineering problems in the new project assignment format in comparison to the previous assignment. In the new format, every team was able to formulate a reasonable engineering problem, even if the actual problems tackled were not particularly ambitious. From this it can be concluded that the structure of the new project probably benefits the students over the unstructured previous project format by helping to guide the students more through the project development process. There were few particular problems noted with the written reports in terms of how well they communicated the project results, and the oral presentations were also adequately clear - thus student outcome $(\mathrm{g})$ was demonstrated by most of the students in the class. Outcome (h) would consider how well the students understood the larger context of their solution, and as noted the students as a whole understood the idea of increasing the value of their engine through improvements or modifications. But most students didn't demonstrate any connection between their designs and global or societal or environmental impacts. However, that isn't surprising as such contexts were not the primary purpose of this project. Lastly, with regards to outcome (k), most student teams used modern tools and 'techniques to some extent in their projects. Some teams did rely on more simplistic analysis techniques, and some teams did have trouble finding available background information on their engines which would not be expected of engineering graduates. As a whole, this project demonstrated partial fulfillment of outcome $(\mathrm{k})$, but a sizeable minority of the class didn't demonstrate this outcome to the level expected of students upon graduation. 
Comparing project grades, or even written report grades, between the revised project and the original project is not meaningful. The report expectations and project deliverables changed with the revision; as a result, one would not expect that the grades would be directly comparable.

Something that should be remembered with these observations is the profile of the typical student in the Mechanical Engineering program. It should be noted that while some students are excellent, there are many students in the program whose academic preparation entering college is not as strong as would be expected of students in most engineering programs. Thus, many of these students have had to struggle with basic math and science concepts to get through their engineering courses. Such efforts may reduce the amount of time that the students and instructors can spend to developing more abstract thinking that might foster greater curiosity and creativity. Therefore, the observations taken from this class are probably most applicable to students who are similarly underprepared for engineering studies when they enter college.

\section{Summary}

In this paper, the results of a redesigned semester-long design project in a course on Internal Combustion Engines were presented. The original project and its shortcomings were described. The project was redesigned for the Spring 2018 semester to try to address some of the shortcomings of the previous project as well as to formally foster students' curiosity and critical thinking skills and to have this lead to greater creativity as students sought to increase the value of a particular engine of their choice. Observations of the results of the student projects during this first use of the new project indicated that most of the shortcomings of the previous project were removed, but that students did not demonstrate (as a whole) much curiosity and developed designs that were mostly short on creativity. The students did understand and execute the idea of adding value to a product through their design, proposing projects to do just that. These lessons will be used to introduce additional material on the desired engineering skills in future course offerings, and to encourage the Mechanical Engineering program at UWM to develop methods throughout the curriculum to encourage more curiosity and critical thinking skills of its students.

\section{Acknowledgements}

The author would like to thank the students in MechEng 432 in the Spring 2018 semester for their willingness to accept the revised assignment and any complications arising from its implementation. Additionally, the College of Engineering and Applied Science at UWM and the UWM Research Foundation are thanked for providing funds for conference travel that led to the creation of this revised project.

References:

1. Prince, M. J., \& Felder, R. M. (2006), Inductive Teaching and Learning Methods: Definitions, Comparisons, and Research Bases. Journal of Engineering Education, 95(2), 123-138 
2. Yousuf, A., \& Mustafa, M., \& De La Cruz, A. (2010, June), Project Based Learning Paper presented at 2010 ASEE Annual Conference \& Exposition, Louisville, Kentucky. https://peer.asee.org/16081

3. Ulseth, R. R., \& Froyd, J. E., \& Litzinger, T. A., \& Ewert, D., \& Johnson, B. M. (2011, June), A New Model of Project-Based Learning in Engineering Education Paper presented at 2011 ASEE Annual Conference \& Exposition, Vancouver, BC. https://peer.asee.org/17360

4. Torres, A., \& Sriraman, V. (2015, June), Project Based Learning in Concrete Industry Project Management Paper presented at 2015 ASEE Annual Conference \& Exposition, Seattle, Washington. 10.18260/p.24599

5. Nespoli, O. G., \& Tempelman, H., \& Spencer, R., \& Lambert, S. (2011, June), Disk Brake Design Case Study Implementation Method and Student Survey Results Paper presented at 2011 ASEE Annual Conference \& Exposition, Vancouver, BC. https://peer.asee.org/17786

6. Krishnan, S., \& Nalim, M. R. (2009, June), Project Based Learning In Introductory Thermodynamics Paper presented at 2009 ASEE Annual Conference \& Exposition, Austin, Texas. https://peer.asee.org/5615

7. David, B., \& Marshall, J. (2017, June), Resolving Epistemological Tension in ProjectBased Introductory Engineering Paper presented at 2017 ASEE Annual Conference \& Exposition, Columbus, Ohio. https://peer.asee.org/28800

8. Bayles, T. (2005, June), Project Based Learning Design Projects For Introduction To Engineering Design Courses Paper presented at 2005 ASEE Annual Conference, Portland, Oregon. https://peer.asee.org/14390

9. Pusca, D. \& Northwood, D.O. (2018). Curiosity, Creativity, and Engineering Education, Global Journal of Engineering Education 20(3), 152-158

10. KEEN, retrieved from https://engineeringunleashed.com

11. ABET, Inc. (2018), Criteria for Accrediting Engineering Programs, 2018-2019, https://www.abet.org/accreditation/accreditation-criteria/criteria-for-accreditingengineering-programs-2018-2019/

12. Pulkrabek, W.W. (2004) Engineering Fundamentals of the Internal Combustion Engine $\left(2^{\text {nd }}\right.$ Ed.). Upper Saddle River, NJ: Pearson 